\title{
Geriatrics Attitudes and Knowledge Among Surgical and Medical Subspecialty House Officers
}

\author{
Lewis P. Krain, MD, ${ }^{*}$ J. Thomas Fitzgerald, PhD, ${ }^{\dagger}$ Jeffrey B. Halter, $M D,{ }^{\ddagger \mathcal{S}}$ and \\ Brent C. Williams, MD, MPH ${ }^{\ddagger}$
}

OBJECTIVES: To examine geriatrics knowledge and attitudes of non-primary care house officers (HOs) before and after a multidisciplinary faculty development program.

DESIGN: Serial cross-sectional surveys.

PARTICIPANTS: HOs.

SETTING: A large midwestern academic medical center.

INTERVENTION: Faculty from seven surgical and six medical subspecialties participated in weekly seminars for 9 months and implemented geriatrics curricula in their HO programs.

MEASUREMENTS: HO geriatrics attitudes and knowledge were measured using the University of California at Los Angeles Geriatrics Attitudes Scale (GAS; 14 items), two scales of the Maxwell Sullivan test (Therapeutic Potential and Time/Energy; six items each; lower scores denote morefavorable attitudes), and the Geriatrics Clinical Knowledge Assessment (20 multiple choice items; range 0-100\%). Repeat surveys were administered in seven disciplines after geriatrics curriculum implementation.

RESULTS: Baseline $(\mathrm{n}=175)$ geriatrics attitudes were favorable (e.g., 3.7 for GAS; 2.1 for Time/Energy), with more-favorable attitudes among medical subspecialty than surgical HOs (e.g., mean GAS 3.8 and 3.6, respectively; $P=.001)$, and with advanced training. Mean baseline knowledge scores were $65.1 \%$ among all HOs. No differences in attitudes or knowledge were observed between the first $(n=100)$ and second $(n=90)$ cohorts in the seven disciplines that administered subsequent tests.

CONCLUSION: Geriatrics attitudes of non-primary care HOs are positive, and knowledge is moderate, suggesting need for and potential effect of geriatrics curricula. Demonstrating effects on learner outcomes of faculty development programs may require more than one faculty member per discipline and measures that are curriculum-

From the Departments of * Psychiatry, ${ }^{\dagger}$ Medical Education, and ${ }^{\dagger}$ Internal Medicine, ${ }^{\S}$ Geriatrics Research and Education Clinical Center, Ann Arbor Veterans Affairs Medical Center, University of Michigan, Ann Arbor, Michigan.

Address correspondence to Brent C. Williams, MD, MPH, 300 N. Ingalls Building, University of Michigan, Ann Arbor, MI 48109.

E-mail: bwilliam@umich.edu

DOI: $10.1111 / \mathrm{j} .1532-5415.2007 .01475 . \mathrm{x}$ specific and detailed rather than general and brief. J Am Geriatr Soc 55:2056-2060, 2007.

Key words: geriatrics; geriatric attitudes; house officer education; faculty development

A merica's aging population is growing rapidly. Physicians who care for adults will be called to treat substantial and increasing numbers of older patients. Despite the need for adequate skills in geriatric care, few residency or fellowship programs for non-primary care house officers (HOs) include more than cursory geriatric content. To address this deficit, the American Geriatrics Society and several specialty societies and philanthropic organizations have called for more training in the care of older adults in the surgical specialties and medical subspecialties (SSMSs). ${ }^{1-3}$

Understanding current geriatrics knowledge and attitudes of HOs in all specialties is essential to developing successful geriatrics curricula. ${ }^{4}$ No data are currently available describing HO knowledge or attitudes in non-primary care training disciplines. Among medical students and residents in primary care specialties, stigma, poor attitudes, and lack of knowledge about treating older patients are common..$^{5,6}$ Other specialties, especially surgery and its subspecialties, have different approaches to patient care and existing knowledge and attitudes data may not generalize to their trainees.

There is also a shortage of qualified geriatrics educators. ${ }^{7,8}$ In other educational settings, faculty development programs have succeeded in enhancing clinical teaching., ${ }^{9,10}$ Faculty development programs in geriatrics have increased curricular time and awareness of issues in geriatrics, but few studies have measured the effects of faculty development on short- or long-term learner outcomes. ${ }^{3}$

To address these needs, the University of Michigan implemented a 4-year program to measure geriatrics knowledge and attitudes in SSMS HOs and enhance training in the care of older adults. The program employed a "train the trainer" model to enhance faculty skills in 
geriatrics care, teaching, and curricular development. Learner outcomes were measured using validated measures of knowledge and attitudes.

This article is the first to describe attitudes and knowledge about geriatrics in HOs across SSMSs. It was expected that HOs in SSMSs would have less-favorable attitudes toward geriatrics than primary care (internal medicine or family medicine) residents or medical students, as reported in previous studies. There are no comparable benchmarks for geriatrics knowledge of SSMS HOs.

\section{METHODS}

\section{Setting and Participants}

The study took place at a large U.S. academic medical center. Participants included $175 \mathrm{HOs}$ from six surgical and related disciplines (SRDs) and seven medically related disciplines (MRDs). With one exception (physical medicine and rehabilitation), specialty classification was based on the classification developed by the American Geriatrics Society. ${ }^{11}$ SRDs were anesthesiology, emergency medicine, general surgery, gynecology, orthopedics, and thoracic surgery, whereas MRDs were endocrinology, gastroenterology, nephrology, oncology, physical medicine, pulmonary and critical care, and rheumatology.

\section{Intervention}

One faculty member from each specialty participated in a weekly half-day educational program in geriatrics clinical care and teaching for 9 months. The chairs of each participating department identified potential faculty participants with the goal of selecting individuals for whom the program was consistent with their career goals and the educational goals of the department. Each half-day consisted of 2 hours of small-group seminars and 2 hours of protected time for individual learning and curriculum development. Participating faculty were divided into three overlapping small groups of four to six individuals over 3 years.

The content of the faculty seminars included four main areas: clinical geriatrics (16 hours), clinical teaching skills (10 hours), curriculum development (6 hours), and program implementation and evaluation (16 hours), with an additional 12 hours of uncategorized content such as evidence-based medicine and professional networking. All the seminars had a geriatrics focus; those covering "general" educational topics concentrated on specific applications of that content to geriatrics education. The seminars used a broad range of instructional techniques, including standard didactics, small-group discussions, participant presentations, role-plays, and works-in-progress written reports. Given wide variation in writing skills, a professional writer was hired to work with faculty participants in completing their writing goals. To develop skills in implementing and evaluating teaching programs, faculty conducted a structured focus group among their learners to identify self-assessed learning needs, following a model previously developed. ${ }^{4}$ In addition, the project director and faculty participants developed and supplemented a geriatrics teaching resources warehouse-a Web-based repository of presentations and reference materials to facilitate development of geriatrics seminars and talks - throughout the project.

Faculty participants implemented new geriatrics curricula in their own departments, including enhanced clinical teaching and didactics. The amount and type of new clinical teaching varied between the disciplines. All participating faculty instituted between two and six new sessions dedicated to geriatrics in their core didactics. Other interventions included new required rotations in a geriatrics clinics (gynecology, physical medicine and rehabilitation, and rheumatology), institution of a half-day geriatrics "retreat" for incoming fellows (endocrinology and rheumatology), and creation of a new combined geriatrics/oncology fellowship (hematology/onocology). All participating faculty included a Geriatrics Standardized Patient Instructor (GSPI) encounter during the program; three departments have continued to administer the GSPI annually to HOs (endocrinology, rheumatology, and physical medicine and rehabilitation). All participating faculty reported more geriatrics teaching during clinical rounds when they were on inpatient and consultation services; this study did not monitor the quantity or quality of these interactions. Obstacles to the consistency of the program included difficulty of some clinicians in freeing their clinical schedules to attend all the sessions (thoracic surgery and urology) and departure of faculty from the institution necessitating recruitment of a replacement faculty member (emergency medicine, gynecology, and rheumatology).

\section{Measures}

HO knowledge and attitudes were assessed using three validated instruments. Geriatrics attitudes were assessed using two subscales from the Maxwell-Sullivan Test ${ }^{12}$ and the University of California at Los Angeles Geriatrics Attitude Scale (GAS). ${ }^{13,14}$ Knowledge level was assessed using the University of Michigan Geriatrics Knowledge Test. ${ }^{15}$ The Maxwell-Sullivan Test consists of five 6-item subscales. Items are scored on a 5-point Likert scale, with lower scores indicating more-positive attitudes. Although there are no specific guidelines to score interpretation, the standard Likert structure using 3 as a neutral anchor allows the inference that scores less than 3 represent positive attitudes and higher than 3 represent negative attitudes. The Maxwell-Sullivan Test has high reliability and validity in training settings, and subsequent studies have used individual subscales as assessment measures. ${ }^{13,16}$ Two subscales measuring $\mathrm{HO}$ attitudes about the effectiveness of therapies among older patients (therapeutic potential; TP) and the time and energy required to care for older patients as compared to younger patients (time and energy; TE) were used. Examples of items from the two subscales are "Elderly patients often fail to follow therapeutic regimens" and "The treatment of elderly patients is too time-consuming," respectively. The GAS measures multiple dimensions of attitudes toward the care of older patients with high internal consistency. ${ }^{14}$ It consists of 14 items scored on a 5-point Likert scale, with higher scores indicating more positive attitudes. A score of 3 is generally considered to indicate a neutral attitude, with higher scores indicating progressively more-favorable attitudes. The GAS has been used in several studies of 
trainees' attitudes. ${ }^{13,17,18}$ The University of Michigan Geriatrics Clinical Decision Making Assessment measures knowledge of recognition and management of a range of clinical problems among older patients commonly encountered by SSMS HOs and has been validated in a four-site study. ${ }^{15}$ It consists of 20 boards-style multiple-choice questions, generating an overall score of $1 \%$ to $100 \%$, with higher score indicating more-complete knowledge. There is no specific pass or fail setpoint for this test; in the initial study involving HOs of several specialties, $\mathrm{HOs}$ in postgraduate year (PGY)-1 scored a mean of $58 \%$, whereas those in PGYs 4 to 7 scored a mean of $69 \%$.

Baseline knowledge and attitudes were measured for all disciplines in a cross-section of HOs before the implementation of the geriatrics curriculum. Repeat administrations were conducted in cross-sectional groups of HOs in seven disciplines at a median of 13 months (range 9-20) from the first administration.

Readers may contact the authors of this paper to obtain copies of all scales used in this study.

\section{Analysis}

Baseline measurements were compared according to year of training and specialty classification (SRD vs MRD) using analyses of variance (ANOVAs) and $t$-tests, respectively (baseline analysis). Ordinary least squares linear regression was used to compare attitudes and knowledge of cohorts of residents before and after curriculum implementation while controlling for year of training and specialty classification (cohort analysis). First-year residents were excluded from the second cohort, because they had less exposure to the new geriatrics curricula. There was significant colinearity between specialty classification and year of training, because essentially all medical subspecialty $\mathrm{HOs}$ were in PGY-4 or higher, and most $(74 \%)$ surgical-related HOs were PGY-3 or lower. Therefore, multivariate analyses included one or the other variable but not both. Scores of individual HOs who participated in baseline and subsequent assessments were made using paired $t$-tests (individual analysis). Limited numbers of observations precluded multivariate modeling in the individual analysis. All analyses were carried out using STATA 9.0 (StataCorp LP, College Station, TX).

\section{RESULTS}

Table 1 shows demographic information at baseline for the 175 participating HOs. Seventy-five percent of the SRD HOs were PGY-1 to 3 , whereas $85 \%$ of the MRD HOs were PGY-4 or greater.

Baseline measurements are shown in Table 2. Baseline attitudes were favorable, with means of 2.19 for TP, 2.12 for TE, and 3.7 for the GAS for all HOs. HOs in MRDs had significantly more positive scores than HOs in SRDs on the GAS and the Maxwell-Sullivan Therapeutic Potential subscale (mean GAS 3.85 vs $3.56, P<.001$; mean TP 2.0 vs $2.19, P=.002$ ). Attitudes were more favorable according to all measures in HOs with advanced training, although slightly lower in those in the PGY 6+ category (ANOVA: TP, $P=.01$; TE, $P=.01$; GAS, $P=.001$ ).

Baseline mean score on the knowledge test was $65.1 \%$ among all HOs. Knowledge scores were higher among the

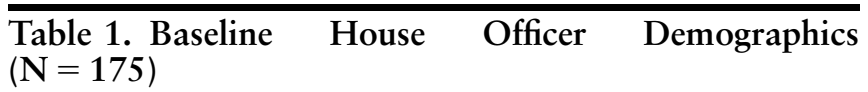

\begin{tabular}{lc}
\hline \multicolumn{1}{c}{ Category } & $\mathbf{n}(\%)$ \\
\hline Program & \\
\hline Anesthesiology & $18(10.3)$ \\
\hline Emergency medicine & $32(18.3)$ \\
\hline Endocrinology & $10(5.7)$ \\
\hline Gastroenterology & $12(7.4)$ \\
\hline General surgery & $14(8.0)$ \\
\hline Obstetrics and gynecology & $12(6.9)$ \\
\hline Oncology & $12(6.9)$ \\
\hline Orthopedic surgery & $22(12.6)$ \\
\hline Physical medicine and rehabilitation & $12(6.9)$ \\
\hline Pulmonary & $11(6.3)$ \\
\hline Thoracic surgery & $6(3.4)$ \\
\hline Other* & $13(7.4)$ \\
\hline Subspecialty & \\
\hline Medically related disciplines ${ }^{\dagger}$ & $67(38.1)$ \\
\hline Surgery and related disciplines ${ }^{\ddagger}$ & $109(61.9)$ \\
\hline SeX & \\
\hline Male & $120(68.6)$ \\
\hline Female & $55(31.4)$ \\
\hline Year of training & $109(62.8)$ \\
\hline PGY 1 & $12(6.9)$ \\
\hline PGY 2 & $7(4)$ \\
\hline PGY 3 & $28(16.0)$ \\
\hline PGY 4 & $40(22.9)$ \\
\hline African & $25(14.3)$ \\
\hline Caucasian & \\
\hline Pnidentified & $36(20.6)$ \\
\hline & $27(15.4)$ \\
\hline & $19(10.9)$ \\
\hline
\end{tabular}

*Includes otolaryngology, nephrology, plastic surgery, rheumatology, and urology.

${ }^{\dagger}$ Includes endocrinology, gastroenterology, nephrology, oncology, physical medicine and rehabilitation, pulmonology, and rheumatology.

${ }^{\ddagger}$ Includes anesthesiology, emergency medicine, general surgery, obstetrics and gynecology, orthopedic surgery, plastic surgery, thoracic surgery, and urology.

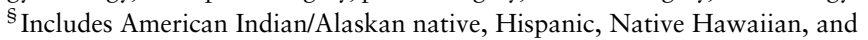
Other.

MRD than SRD HOs (68.88 vs $62.71, P=.002)$ and those with more-advanced training (ANOVA $P=.01$ ).

No significant differences were found in attitudes or the knowledge between the first $(n=100)$ and second $(n=90)$ cohorts in the seven disciplines that repeated the assessment instruments after controlling for year of training (data not shown).

Of the 61 individual HOs who completed the assessment more than once, the Maxwell-Sullivan TE subscale showed significant improvement after the initiation of the faculty development program (mean 2.17 vs $2.08, P=.04$ ). No other changes in attitudes or knowledge were observed, 
Table 2. House Officer Attitudes and Knowledge Scores at Baseline $(\mathbf{n}=175)$

\begin{tabular}{lcccc}
\hline \multicolumn{1}{c}{ Instrument } & $\begin{array}{c}\text { All } \\
\text { House } \\
\text { Officers }\end{array}$ & $\begin{array}{c}\text { Medically } \\
\text { Related } \\
\text { Disciplines }\end{array}$ & $\begin{array}{c}\text { Surgery and } \\
\text { Related } \\
\text { Disciplines }\end{array}$ & P-Value* \\
\hline Geriatric Attitude Scale & 3.67 & 3.85 & 3.56 & $<.001$ \\
Therapeutic potential & 2.19 & 2.12 & 2.23 & .09 \\
Time and energy & 2.12 & 2 & 2.19 & .002 \\
Knowledge test & 65.06 & 68.88 & 62.71 & $<.001$ \\
\hline
\end{tabular}

${ }^{*} t$-test.

although increases in knowledge test scores approached significance (mean 65.97 vs $69.03, P=.06$ ).

\section{DISCUSSION}

This is the first study of attitudes and knowledge about geriatric care among HOs in SSMSs. Geriatrics attitudes of HOs in MRD and SRD specialties were favorable. For example, the Maxwell-Sullivan scores used in this study are equivalent to or slightly better than those reported at other institutions among medical students and primary care HOs. Specifically, scores of SRD and MRD PGY-1 to 3 HOs in this study (TP, 2.21; TE, 2.31) were better than those for starting medical interns (overall score 2.8) ${ }^{19}$ and roughly equivalent to scores of first-year medical students (TP, 2.59; TE, 2.14) ${ }^{16,20}$ in other studies. Similarly, scores on the GAS in this study (3.7) were favorable and similar to published scores of approximately 4.0 among first-year medical students, 3.5 to 3.6 for PGY-1s in primary care specialties, and approximately 4.0 in fellows in geriatric medicine. ${ }^{17,18}$

There were few significant improvements in knowledge or attitudes in the cohort or individual $\mathrm{HO}$ analyses. The observed trends toward improving attitudes and knowledge in individual HOs over time may be due to the effect of increasing experience. The lack of change in $\mathrm{HO}$ attitudes and knowledge before and after implementation of the geriatrics curricula may be due to several factors. First, the geriatrics curricula were not standardized but rather were purposely flexible so as to be relevant to a particular training program. Faculty developed their lectures and clinical teaching based on discipline-specific learner needs assessments and their own judgment, without awareness of the items in the knowledge test. Faculty may have focused on material not contained in the brief 20-item knowledge test. In addition, some departments had more difficulty than others in instituting a geriatrics curriculum because of the faculty turnover and scheduling complications described above. It is possible that the curricula were less effective in these departments, diluting the overall effect of the intervention. Second, because baseline attitudes were positive, there may have been a ceiling effect, limiting the amount of improvement in attitudes. Finally, the effects of a single faculty members' teaching are likely to be small in the context of the large number of $\mathrm{HO}$ learning experiences over a 1- to 2-year period.

These results are valuable as a guide to future efforts in geriatrics education at the University of Michigan and at other institutions. Given the diverse nature of the faculty and HOs, the experience and data gathered are reflective of the academic environment across the nation. In the future, a more-intensive faculty development program may be required to produce a measurable change in learner knowledge or attitudes. Also, a single faculty member within a discipline may not have enough exposure to HOs to change their knowledge or attitudes; future interventions should attempt to train at least two faculty in each discipline to create a critical mass of geriatrics expertise within each department or division. Initiatives from the American Geriatrics Society to enhance educational opportunities for faculty in geriatrics can support such efforts. Examples include the Dennis W. Jahnigen Career Development Scholars Program, which supports geriatrics education for faculty in surgery and related specialties, ${ }^{21}$ and the T. Franklin Williams Scholars award, which supports collaboration between geriatricians and colleagues in internal medicine. ${ }^{22}$ Finally, it is unknown whether teaching by geriatrics specialists rather than discipline-specific faculty would have enhanced these outcomes. The premise of this study was that teaching by discipline-specific faculty is essential to enhance credibility among the learners and ensure long-term culture change in participating departments.

Inability of the scales to find a measurable effect shows that evaluations should be tightly modified to the specific intervention provided by each faculty rather than to general knowledge assessments. More clinically oriented assessments, such as a pre/post objective structured clinical examination or standardized patient examination, may have greater sensitivity for changes in knowledge and attitudes.

\section{CONCLUSION}

Positive attitudes scores among SSMS HOs combined with low knowledge scores suggest that educational programs in geriatrics are needed and will be well received by $\mathrm{HOs}$ in SSMSs.

This study provides insight into the development of future interventions to teach care of older patients in SSMSs. Successful interventions must train enough faculty to expose HOs to geriatrics content throughout their training. It is likely that faculty must be engaged in ongoing training in clinical care and teaching methods relevant to the care of older patients, such as meetings or journal clubs. Also, objective measures of learner outcomes to measure the effect of new geriatrics curricula should include brief, general measures that provide a broad picture of learners knowledge, skills, and attitudes and more-detailed instruments directed at the content of specific teaching programs.

\section{ACKNOWLEDGMENTS}

Conflict of Interest: This study was supported by a grant from the D. W. Reynolds Foundation and the University of Michigan Medical School. None of the authors have financial interests, consultantships, positions on speakers forums, personal company holdings, or patents relevant to this research.

Author Contributions: Lewis Krain: analysis and interpretation of data, preparation of manuscript. J. Thomas Fitzgerald and Brent Williams: study concept, study design, acquisition of subjects and data, analysis and interpretation 
of data, preparation of manuscript. Jeffrey Halter: study concept, study design, acquisition of subjects.

Sponsor's Role: The Reynolds Foundation played no role in the design, methods, subject recruitment, data collection, analysis, or preparation of this manuscript.

\section{REFERENCES}

1. United States Department of Health and Human Services Administration on Aging. Statistics on the aging population [on-line]. Available at http:// www.aoa.gov/prof/Statistics/statistics.asp Accessed March 13, 2006.

2. American Geriatrics Society Core Writing Group for the Task Force on the Future of Geriatric Medicine. Caring for older Americans: The future of geriatric medicine. J Am Geriatr Soc 2005;53:S245-S256.

3. Potter JF, Burton JR, Drach GW et al. Geriatrics for residents in the surgical and medical subspecialties: Implementation of curricula and training experiences. J Am Geriatr Soc 2005;53:511-515.

4. Kern D, Thomas P, Howard D et al. Curriculum Development for Medical Education: A Six-Step Approach. Baltimore, MD: Johns Hopkins University Press, 1998.

5. Landefeld CS, Callahan CM, Woolard N. General internal medicine and geriatrics: Building a foundation to improve the training of general internists in the care of older adults. Ann Intern Med 2003;139:609-614.

6. Shue CK, McNeley K, Arnold L. Changing medical students' attitudes about older adults and future older patients. Acad Med 2005;80:S6-S9.

7. Warshaw G, Bragg E, Shaull R et al. Geriatric medicine fellowship programs: A national study from the Association of Directors of Geriatric Academic Programs' longitudinal study of training and practice in geriatric medicine. J Am Geriatr Soc 2003;51:1023-1030.

8. Rubin CD, Stieglitz H, Vicioso B et al. Development of geriatrics-oriented faculty in general internal medicine. Ann Intern Med 2003;139:615-620.

9. Hewson MG, Copeland HL. Outcomes assessment of a faculty development program in medicine and geriatrics. Acad Med 1999;74:S68-S70.
10. Peters AS, Ladden MD, Kotch JB et al. Evaluation of a faculty development program in managing care. Acad Med 2002;77:1121-1127.

11. Solomon DH, Burton JR, Lundebjerg NE et al. The new frontier: Increasing geriatrics expertise in surgical and medical specialties. J Am Geriatr Soc 2000;48:702-704.

12. Maxwell AJ, Sullivan N. Attitudes toward the geriatric patient among family practice residents. J Am Geriatr Soc 1980;28:341-345.

13. Boal J, Fabacher D, Miller R et al. Validation of an instrument designed to assess medical student attitudes toward home care. J Am Geriatr Soc 2001;49:479-473.

14. Reuben DB, Lee M, Davis JW et al. Development and validation of a geriatrics attitudes scale for primary care residents. J Am Geriatr Soc 1998;46: 1425-1430.

15. Williams BC, Fitzgerald JT. Brief instrument to assess geriatric knowledge of surgical and medical subspecialty house officers. J Gen Intern Med 2006;21: 490-493.

16. Roscoe LA, Schonwetter RS, Walalch PM. Advancing geriatrics education: Evaluation of a new curricular initiative. Teach Learn Med 2005;17:355-362.

17. Kishimoto M, Nagoshi M, Williams S et al. Knowledge and attitudes about geriatrics of medical students, internal medicine residents, and geriatric medicine fellows. J Am Geriatr Soc 2005;53:99-102.

18. Lee M, Reuben DB, Ferrell BA. Multidimensional attitudes of medical residents and geriatrics fellows toward older people. J Am Geriatr Soc 2005;53:489-494.

19. Maurer MS, Costley AW, Miller PA et al. The Columbia cooperative aging program; an interdisciplinary and interdepartmental approach to geriatric education for medical interns. J Am Geriatr Soc 2006;54:520-526.

20. Fitzgerald JT, Wray LA, Halter JB et al. Relating medical students' knowledge, attitudes, and experience to an interest in geriatric medicine. Gerontologist 2003;43:849-855.

21. American Geriatrics Society. 2007 Dennis W. Jahnigen career development scholars awards [on-line]. Available at http://www.americangeriatrics.org/ hartford/jahnigen.shtml Accessed May 20, 2007.

22. American Geriatics Society. 2007, T. Franklin Williams research scholars award [on-line]. Available at http://www.healthinaging.org/franklin_Williams/ Accessed May 20, 2007. 